\title{
High-Throughput Syntheses of Iron Phosphite Open Frameworks in
}

\section{Ionic Liquids}

\author{
Zhixiu Wang ${ }^{[\mathrm{a}]}$, Ying $\mathrm{Mu}^{[\mathrm{b}]}$, Yilin Wang ${ }^{[\mathrm{b}]}$, Qiming Bing ${ }^{[\mathrm{a}]}$, Tan $\mathrm{Su}^{[\mathrm{a}, \mathrm{b}]^{*}}$, Jingyao Liu ${ }^{[\mathrm{a}]}$ \\ [a] Laboratory of Theoretical and Computational Chemistry, Institute of Theoretical Chemistry, Jilin University, Changchun 130021, \\ P. R. China \\ [b] State Key Laboratory of Inorganic Synthesis and Preparative Chemistry, College of Chemistry, Jilin University, Changchun \\ 130012, P. R. China
}

Submitted to Solid State Sciences as a full paper

Corresponding Author:

Dr. Tan $\mathrm{Su}$

E-mail: sutan_jlu@jlu.edu.cn

Fax: +86-0431-88498016

Tel.: +86-0431-88498016 
Abstract Three open-framework iron phosphites: $\mathrm{Fe}_{5}^{\mathrm{\Pi}}\left(\mathrm{NH}_{4}\right)_{2}\left(\mathrm{HPO}_{3}\right)_{6}(\mathbf{1}), \mathrm{Fe}_{2}^{\mathrm{\Pi}} \mathrm{Fe}^{\mathrm{m}}\left(\mathrm{NH}_{4}\right)\left(\mathrm{HPO}_{3}\right)_{4}(\mathbf{2})$ and $\mathrm{Fe}_{2}^{\mathrm{m}}\left(\mathrm{HPO}_{3}\right)_{3}(\mathbf{3})$ have been synthesized under ionothermal conditions. How the different synthesis parameters, such as the gel concentrations, synthetic times, reaction temperatures and solvents affect the products have been monitored by using high-throughput approaches. Within each type of experiment, relevant products have been investigated. The optimal reaction conditions are obtained from a series of experiments by high-throughput approaches. All the structures are determined by single-crystal X-ray diffraction analysis and further characterized by PXRD, TGA and FTIR analyses. Magnetic study reveals that those three compounds show interesting magnetic behavior at low temperature.

Keywords Ionic liquids; High-throughput; Open Framework; Iron phosphite; Mössbauer measurement; Magnetic behavior

\section{Introduction}

The discovery of new structures needs a large amount of experimental efforts, which can be diminished by using high-throughput approaches. In the synthesis procedure, the application of high-throughput approaches for materials science can help researchers to rapid screen the variables, raising the number of samples produced and characterized [1-3]. In 1998, Wendelbo's group [4] presented the high-throughput technique into zeolite syntheses, which has showed its formidable strength in the fast optimization of synthetic conditions of known zeolites [5-7] and in the discovery of new structures [8-10]. Many metal phosphates [11-16] have attracted much attention because of their unique physical and chemical properties in optics, electronics and magnetism, and exhibited great potential applications in the fields of separation, adsorption and catalysis [17, 18] due to various metal ions doped in these compounds. Lately, using phosphite group to replace tetrahedral phosphate group to afford new metal phosphites have attracted great attention [19]. Lots of metal phosphites have been synthesized and characterized, such as zinc phosphites [20-22], vanadium phosphites [23-26], cobalt phosphites [27-33], manganese phosphites $[34,35]$ and iron phosphites [36-57]. Among these materials, iron phosphites occupied a considerable position because of its rich diversity of structures and special magnetic properties. Notable examples includes, $\left|\mathrm{C}_{10} \mathrm{~N}_{2} \mathrm{H}_{8}\right|\left[\mathrm{Fe}^{\mathrm{WI}}\left(\mathrm{HPO}_{3}\right)\left(\mathrm{H}_{2} \mathrm{PO}_{4}\right)\right]$ [40], the first 1D iron phosphite-phosphate with an antiferromagnetic character, $\left|\mathrm{C}_{4} \mathrm{H}_{12} \mathrm{~N}_{2}\right|\left[\mathrm{Fe}^{\mathrm{I}} \mathrm{Fe}^{\mathrm{II}}\left(\mathrm{HPO}_{3}\right)_{2} \mathrm{~F}_{3}\right]$ [43], an iron phosphite with a mixed valence nature and antiferromagnetic property, $\left|\mathrm{C}_{4} \mathrm{~N}_{3} \mathrm{H}_{14}\right|\left[\mathrm{Fe}_{3}\left(\mathrm{HPO}_{3}\right)_{4} \mathrm{~F}_{2}\left(\mathrm{H}_{2} \mathrm{O}\right)_{2}\right]$ [50], and a new 3D iron phosphite with an antiferromagnetic property. Typically, metal phosphites were synthesized under hydrothermal or solvothermal conditions.

In 2004, Morris and co-workers developed the ionothermal method for syntheses of inorganic open-framework materials [58] for the first time. In recent decade, a number of studies on the usage of ionic liquids as the solvent and structure-directing agent to synthesize microporous aluminum phosphate molecular sieves were reported [59-64]. Ionic liquids are a class of organic molten salts, which are completely constituted by ions at room temperature and adjacent temperature $[65,66]$. The reaction possess negligible vapor pressure, which in sealed autoclaves is safe [67]. There are other potential advantages of ionothermal method, such as it can improve the templating effect, which can reduce the competition between solvent and template for their interaction with coordinate atoms [68], and also this route may generate a series of new structures [69-75]. For instance, Yu's group has reported the ionothermal synthesis of $5 \mathrm{H}_{3} \mathrm{O} \cdot\left[\mathrm{Ni}_{8}\left(\mathrm{HPO}_{3}\right)_{9} \mathrm{Cl}_{3}\right] \cdot 1.5 \mathrm{H}_{2} \mathrm{O}$ [74], a nickel phosphite shows antiferromagnetic property and $\left|\mathrm{NH}_{4}\right|_{4}\left[\mathrm{Mn}_{4}\left(\mathrm{HPO}_{3}\right)_{6}\right]$ [75], a new 2D manganese(II) phosphite with an 
antiferromagnetic dimer system.

To date, the ionothermal synthesis of metal doped phosphites by high-throughput technique have not been studied widely, which inspired us to use this method to synthesize innovative phosphite open-framework materials. In this manuscript, we report three iron phosphites by using high-throughput technique, named, $\mathrm{Fe}_{5}{ }_{5}\left(\mathrm{NH}_{4}\right)_{2}\left(\mathrm{HPO}_{3}\right)_{6}(\mathbf{1})$, $\mathrm{Fe}_{2}{ }_{2} \mathrm{Fe}^{\mathrm{E}}\left(\mathrm{NH}_{4}\right)\left(\mathrm{HPO}_{3}\right)_{4}$ (2) and $\mathrm{Fe}_{2}{ }_{2}\left(\mathrm{HPO}_{3}\right)_{3}$ (3) respectively. The ionothermal syntheses, crystal structures, thermogravimetric analyses, magnetic and Mössbauer analyses of the compounds are reported.

\section{Experimental section}

\subsection{Reagents and physicochemical characterization techniques}

Phosphorous acid (AR, purity 99\%, Sinopharm Chemical Reagent Co., Ltd), iron(III) oxalate hexahydrate (Alfa Aesar), ionic liquids (prepared by ourselves), deionized water, all the chemicals were used as-purchased and without further purification.

The powder X-ray diffraction (PXRD) patterns were collected on a Rigaku D/MAX-IIIA diffractometer. Inductively coupled plasma (ICP) analysis was performed on a Perkin-Elmer Optima 3300DV spectrometer. The elemental analysis was conducted on a Perkin-Elmer 2400 elemental analyzer. Infrared spectra was performed using the $\mathrm{KBr}$ pellet method: 2 or $3 \mathrm{mg}$ of each compound were mixed with $\mathrm{KBr}$ powder and pressed to form a pellet which was analyzed by a Nicolet Impact 410 FTIR spectrometer in the range $400-4000 \mathrm{~cm}^{-1}$. Thermogravimetric measurements were performed on Perkin-Elmer TG-7 thermal analyzer in $\mathrm{N}_{2}$ with the heating rate of $10{ }^{\circ} \mathrm{C} / \mathrm{min}^{-1}$. The magnetization was measured over the temperature range of $2-300 \mathrm{~K}$ for the title compounds, using a Quantum Design MPMS-XL SQUID magnetometer. Mössbauer measurement was made on the OXFORD MS-500 instrument at room temperature using a conventional constantacceleration spectrometer with $\mathrm{a}^{57} \mathrm{Co} / \mathrm{Pd}$ source and the velocity of isomer shifts is calibrated by the $\alpha$-Fe foil.

\subsection{Synthesis}

In this work, we have investigated the following issues:

1) How the gel concentrations, synthetic times and reaction temperatures affect the synthesis process. So a series of different synthesis reaction paths were designed by the high-throughput approaches. By controlling different reaction temperatures, different reaction times and different $\mathrm{Fe} / \mathrm{P}$ ratios, three iron phosphites open-framework $\mathrm{Fe}_{5}{ }_{5}\left(\mathrm{NH}_{4}\right)_{2}\left(\mathrm{HPO}_{3}\right)_{6}(\mathbf{1}), \mathrm{Fe}_{2}{ }_{2} \mathrm{Fe}^{\mathrm{m}}\left(\mathrm{NH}_{4}\right)\left(\mathrm{HPO}_{3}\right)_{4}(\mathbf{2})$ and $\mathrm{Fe}_{2}^{\mathrm{m}}{ }_{2}\left(\mathrm{HPO}_{3}\right)_{3}(\mathbf{3})$ have been obtained. For each compound, we have selected the best reaction conditions which can generate the pure phase, and only one variable parameter has been changed for each specific condition. Specially, we found that the compound $\mathbf{1}$ was produced as the increase of reaction temperature but its crystallinity decreased. All the reaction results are listed in Table 1 . The following is the optimal reaction conditions for our synthesis.

2) Based on the optimal reaction routes, the effects of different ionic liquids [69] on the products were also studied. The results are listed in Table 2. From this table, we can see that the use of small steric hindrance solvent ([Emim] $\mathrm{Br}$ ) is more conducive to produce target products in the reaction, the phase of $\mathrm{Fe}_{2}^{\mathrm{II}}\left(\mathrm{HPO}_{3}\right)_{3}(3)$ and amorphism are more easily generated by using other ionic liquids as solvents and template agents.

\subsubsection{Synthesis of compound 1}

Compound 1 was prepared under mild ionothermal conditions and autogenous pressure. The starting reagents were 1-ethyl-3-methylimidazolium bromide $([\mathrm{Emim}] \mathrm{Br})(5.23 \mathrm{mmol}), \mathrm{H}_{3} \mathrm{PO}_{3}(2.44 \mathrm{mmol}), \mathrm{Fe}_{2}\left(\mathrm{C}_{2} \mathrm{O}_{4}\right)_{3} \cdot 6 \mathrm{H}_{2} \mathrm{O}(0.455$ 
mmol). The mixture was stirred to assure homogeneity, sealed in a $15 \mathrm{ml}$ PTFE-lined stainless steel pressure vessel and heated at $160{ }^{\circ} \mathrm{C}$ for 20 days, followed by slow cooling to room temperature. The well-formed medium crystals were separated and washed with deionized water and dried at $60{ }^{\circ} \mathrm{C}$ in oven.

\subsubsection{Synthesis of compound 2}

Compound 2 was prepared under mild ionothermal conditions and autogenous pressure. The starting reagents were 1-ethyl-3-methylimidazolium bromide ([Emim]Br) $(5.23 \mathrm{mmol}), \mathrm{H}_{3} \mathrm{PO}_{3}(2.44 \mathrm{mmol}), \mathrm{Fe}_{2}\left(\mathrm{C}_{2} \mathrm{O}_{4}\right)_{3} \cdot 6 \mathrm{H}_{2} \mathrm{O}(0.331$ $\mathrm{mmol})$. The mixture was stirred to assure homogeneity, sealed in a $15 \mathrm{ml}$ PTFE-lined stainless steel pressure vessel and heated at $150{ }^{\circ} \mathrm{C}$ for 15 days, followed by slow cooling to room temperature. The well-formed medium crystals were separated and washed with deionized water and dried at $60{ }^{\circ} \mathrm{C}$ in oven.

\subsubsection{Synthesis of compound $\mathbf{3}$}

Compound 3 was prepared under mild ionothermal conditions and autogenous pressure. The starting reagents were 1-ethyl-3-methylimidazolium bromide ([Emim]Br) $(5.23 \mathrm{mmol}), \mathrm{H}_{3} \mathrm{PO}_{3}(2.44 \mathrm{mmol}), \mathrm{Fe}_{2}\left(\mathrm{C}_{2} \mathrm{O}_{4}\right)_{3} \cdot 6 \mathrm{H}_{2} \mathrm{O}(0.269$ $\mathrm{mmol})$. The mixture was stirred to assure homogeneity, sealed in a $15 \mathrm{ml}$ PTFE-lined stainless steel pressure vessel and heated at $140{ }^{\circ} \mathrm{C}$ for 10 days, followed by slow cooling to room temperature. The well-formed medium crystals were separated and washed with deionized water and dried at $60{ }^{\circ} \mathrm{C}$ in oven.

\subsection{Single crystal structure determination}

The single-crystal diffraction data were collected at room temperature on a Siemens Smart CCD diffractometer using graphite-monochromated Mo-K $\alpha(\lambda=0.71073 \AA)$ radiation operating at $20 \pm 2{ }^{\circ} \mathrm{C}$. The data reduction was realized with SAINT program [76], the structure was solved and refined using the SHELXTL-97 suit of programs [77]: First, the space group and the atomic position of the skeleton $\mathrm{T}(\mathrm{Fe}, \mathrm{P})$ is determined by direct method, then all non-hydrogen atoms coordinates are calculated by the difference function techniques and the least-squares techniques. The direct method solution readily revealed sufficient fragments of the structure (Fe, $\mathrm{P}$ and $\mathrm{O})$. The protonated hydrogen atom of the ammonium ion formed after template decomposition and the hydrogen atom on the $\mathrm{P}-\mathrm{OH}$ group can be found in the theoretical hydrogenation or in the difference Fourier-map. The crystal and experimental data of three compounds are listed in Table 3 and Table S1-S9.

\section{Results and discussion}

\subsection{Description of the crystal structure}

\subsubsection{The crystal structure of compound 1}

As shown in Fig. 1(1), the powder X-ray diffraction pattern of the compound $\mathbf{1}$ is in good agreement with the one simulated based on the data of the single-crystal structure. The diffraction peaks on both patterns correspond well in position, indicating the phase purity of the as-synthesized product.

For compound 1, it crystallizes in the trigonal $P \overline{3} c 1$ space group, which is isomorphous with the compound synthesized by hydrothermal method [56]. The asymmetric unit of compound $\mathbf{1}$ is displayed in Fig. S1, it contains two crystallographically distinct $\mathrm{Fe}$ atoms. Both $\mathrm{Fe}$ atoms are octahedrally coordinated to $\mathrm{O}$ atoms. $\left[\mathrm{FeO}_{6}\right]$ 
octahedra are linked together by edge-sharing giving rise to grids parallel to [001] direction, where 12-membered rings are enclosed by six $\left[\mathrm{Fe}(1) \mathrm{O}_{6}\right]$ octahedra and six $\left[\mathrm{Fe}(2) \mathrm{O}_{6}\right]$ octahedral. The crystal structure of compound $\mathbf{1}$ is shown in Fig. 2(a, b), the $\left[\mathrm{FeO}_{6}\right]$ grids are further connected via $\left[\mathrm{HPO}_{3}\right]$. Along the [001] direction, six anions share the most interior oxygen atoms in each 12-membered ring. The $\mathrm{P}$ atom of the complex oxoanion is located on a general position of this space group and the ammonium cations are located in the 12-membered channels. But because of the positional disorder, no hydrogen is fixed to the root of the ammonium. It is worth mentioning that the ammonium cation is decomposed by ionic liquid, other ammonium source has not been added to this reaction. In the reaction, ionic liquid plays dual roles of template agent and solvent.

\subsubsection{The crystal structure of compound 2}

As also shown in Fig. 1(2), the powder X-ray diffraction pattern of the compound $\mathbf{2}$ is in good agreement with the one simulated based on the data of the single-crystal structure. The diffraction peaks on both patterns correspond well in position, indicating the phase purity of the as-synthesized product.

The compound 2 displays a 3D open-framework and the compound crystallizes in the monoclinic space group $P 2{ }_{1} / c$, which is isomorphous with the compound synthesized by hydrothermal method [38]. The asymmetric unit of the product is showed in Fig. S2. It contains three crystallographically inequivalent Fe atoms and four crystallographically inequivalent $\mathrm{P}$ atoms. In addition, the ammonium ion is located in the channel to balance the charge, which might be derived from the decomposition of ionic liquid. Notably, three crystallographically independent $\mathrm{Fe}$ atoms are in different valence states verified by bond valence calculation and Mössbauer spectroscopic measurements, which will be discussed later. The $\mathrm{Fe}(1)$ and $\mathrm{Fe}(2)$ atom are divalent and the $\mathrm{Fe}(3)$ atom is trivalent, each $\mathrm{Fe}$ atom takes octahedral coordination geometry with six oxygen donor atoms from $\left[\mathrm{HPO}_{3}\right]$ units. The Fe-O bond distances are in the range of 1.948(3) and 2.312(3) $\AA$. The selected bond lengths and angles of compound 2 are listed in Table S5.

The structure of compound 2 is formed by the linkage of $\left[\mathrm{FeO}_{6}\right]$ octahedra and $\left[\mathrm{HPO}_{3}\right]$ tetrahedra. Each $\left[\mathrm{FeO}_{6}\right]$ octahedron is connected with $\left[\mathrm{HPO}_{3}\right]$ pseudo-pyramids, showing a 10-membered ring along the [001] direction. $\left[\mathrm{Fe}^{\mathrm{n}} \mathrm{O}_{6}\right]$ octahedra show spiral chain growth along the [010] direction, and $\left[\mathrm{Fe}^{\mathrm{m}} \mathrm{O}_{6}\right]$ octahedra are grown by a chain along the longitudinal direction. These two $\left[\mathrm{FeO}_{6}\right]$ chains are alternatively connected via $\left[\mathrm{HPO}_{3}\right]$ pseudo tetrahedral units, resulting in a three-dimensional iron phosphite backbone (as shown in Fig. 3(b, c).) The results of the inductively coupled plasma (ICP) test show that: $\mathrm{Fe}, 33.46 \%$; P, $24.45 \%$ (calculated for $\mathrm{Fe}_{3} \mathrm{H}_{8} \mathrm{NO}_{12} \mathrm{P}_{4}$ : Fe, $33.20 \% ; \mathrm{P}, 24.51 \%$ ) and the elemental analysis show: $\mathrm{N}, 2.390 \% ; \mathrm{H}, 1.765 \%$ (calculated for $\mathrm{Fe}_{3} \mathrm{H}_{8} \mathrm{NO}_{12} \mathrm{P}_{4}: \mathrm{N}$, $2.77 \% ; \mathrm{H}, 1.58 \%$ ), these results match with the molecular formula analyzed by the single crystal diffraction data.

Mössbauer spectroscopy at ambient temperature was also performed to confirm the simultaneous existence of $\mathrm{Fe}^{2+}$ and $\mathrm{Fe}^{3+}$ cations in compound 2 (Fig. 3(a)). The three lines (green, blue and purple) are in good agreement with those expected for $\mathrm{Fe}^{2+}$ and $\mathrm{Fe}^{3+}$ ions in octahedral coordination, which is consistent with the crystal structure analysis and the bond-valence calculations. The isomer shift and quadrupole splitting values in compound $\mathbf{2}$ is shown in Table 4, and the ratio of $\mathrm{Fe}(1): \mathrm{Fe}(2): \mathrm{Fe}(3)$ is close to 1(Table 4), according to their crystallographic multiplicities. It can be clearly seen that the $\mathrm{Fe}^{\mathrm{I}}$ and $\mathrm{Fe}^{\mathrm{m}}$ coexist in compound $\mathbf{2}$.

\subsubsection{The crystal structure of compound 3}

As also shown in Fig. 1(3), the powder X-ray diffraction pattern of the compound $\mathbf{3}$ is in good agreement with the one simulated based on the data of the single-crystal structure. The diffraction peaks on both patterns correspond well in position, indicating the phase purity of the as-synthesized product. 
For compound 3, it crystallizes in the hexagonal $P 6_{3} / m$ space group, which is isomorphous with the compound synthesized by hydrothermal method [44]. The asymmetric unit of the product is showed in Fig. S3. The graph contains one crystallographically distinct $\mathrm{Fe}$ atom and one crystallographically distinct $\mathrm{P}$ atom. The $\left[\mathrm{Fe}^{\mathrm{W}} \mathrm{O}_{6}\right]$ octahedra are linked by $\left[\mathrm{HPO}_{3}\right]$ to form a four-membered ring, the edge-sharing $\left[\mathrm{Fe}^{\mathrm{w}} \mathrm{O}_{6}\right]$ dimers exist in the [100] direction. The dimers are linked alternatively with the $\left[\mathrm{HPO}_{3}\right]$ pseudo-pyramids, which constitutes a three-dimensional iron phosphite open- framework (as shown in Fig. 4(a, b)). The results of the inductively coupled plasma (ICP) test show that: $\mathrm{Fe}, 30.71 \%$; P, $28.80 \%$ (calculated for: $\mathrm{Fe}, 31.53 \%$; P, $26.44 \%$ ), which matches with the molecular formula analyzed by the single crystal diffraction data.

\subsection{Infrared(IR) spectra}

The IR spectra (Fig. 5) of compounds 1, 2 and $\mathbf{3}$ were partially similar and showed typical peaks, with little differences in the spectra. The bands in the region $2395-2520 \mathrm{~cm}^{-1}$ for compound $1,2400-2500 \mathrm{~cm}^{-1}$ for compound 2 and 2379-2493 $\mathrm{cm}^{-1}$ for compound $\mathbf{3}$ can be assigned to the vibrations of the phosphite $\mathrm{P}-\mathrm{H}$ group and the bands in the region. 1106-460 $\mathrm{cm}^{-1}$ for compound $1,620-1180 \mathrm{~cm}^{-1}$ for compound 2 and $1000-1180 \mathrm{~cm}^{-1}$ for compound 3 can be assigned to the vibrations of the phosphite $\mathrm{P}-\mathrm{O}$ group. While the bands at $3650-2850 \mathrm{~cm}^{-1}, 1460 \mathrm{~cm}^{-1}$ for compound 1 and $3550-2900 \mathrm{~cm}^{-1}, 1465 \mathrm{~cm}^{-1}$ for compound 2 can be assigned to the vibrations of the $\mathrm{NH}_{4}{ }^{+}$groups.

\subsection{Thermogravimetric analysis}

\subsubsection{The thermogravimetric analysis of compound 1}

The stability of compound $\mathbf{1}$ was measured by thermogravimetric analysis (TGA) and differential thermal analysis (DTA). The thermal behavior is shown in Fig. S4. The red curve represents the TGA data and the blue curve is the DTA results. From this figure we can see that from 312 to $862 \mathrm{~K}$, there is a slow decrease in the TGA curve, with the weight loss of $12.31 \mathrm{wt} \%$, this change might come from the removal of residual and adsorbed water, the loss of $\mathrm{NH}_{4}{ }^{+}$and the process of generating stable oxides. This phenomenon is in good accord with the molecular formula.

\subsubsection{The thermogravimetric analysis of compound 2}

In order to test the stability of compound 2, thermogravimetric analysis (TGA) and differential thermal analysis (DTA) were performed on compound $\mathbf{2}$. The results are shown in Fig. S5. The red curve represents the TGA data and the blue curve is the DTA results. From this figure we can see that the weight loss is $0.24 \mathrm{wt} \%$ before $523 \mathrm{~K}$, this change might arise from the removal of residual and adsorbed water. From 603 to $703 \mathrm{~K}$, there is an endothermic peak on the DTA curve, which corresponds to a sharp decrease in the TGA curve, this phenomenon is attributed to the loss of $\mathrm{NH}_{4}{ }^{+}$. Up to $833 \mathrm{~K}$, the weight loss is $3.34 \mathrm{wt} \%$, which is in good agreement with the calculated value $3.36 \mathrm{wt} \%$. From 833 to $873 \mathrm{~K}$, there is an exothermic peak in the DTA curve, which corresponds to a slow decrease in the TGA curve, this phenomenon is attributed to the collapse of compound $\mathbf{2}$, which is a process of generating stable oxides. This phenomenon is in good accord with the molecular formula, which indicates the compound $\mathbf{2}$ have better stability in the phosphite family.

\subsubsection{The thermogravimetric analysis of compound $\mathbf{3}$}

The stability of compound $\mathbf{3}$ was measured by thermogravimetric analysis (TGA) and differential thermal analysis (DTA). The thermal behavior is shown in Fig. S6. The red curve represents the TGA data and the blue curve is the 
DTA results. From this figure we can see that the weight loss is $0.56 \mathrm{wt} \%$ before $609 \mathrm{~K}$, which might be caused by the removal of residual and adsorbed water. From 609 to $826 \mathrm{~K}$, there is a sharp decrease in the TGA curve, the weight loss is $1.97 \mathrm{wt} \%$, this phenomenon is attributed to the collapse of compound $\mathbf{3}$.

\subsection{Magnetic properties}

\subsubsection{Magnetic properties of compound 1}

The temperature dependence of the magnetic measurement was performed on compound $\mathbf{1}$ in a temperature range from 2 to $300 \mathrm{~K}$ with an applied field of $5 \mathrm{kOe}$. Fig. S7 shows the temperature dependence of magnetic susceptibility measurements for the compound 1 in the form of $\chi_{\mathrm{m}} T$ and $1 / \chi_{\mathrm{m}}$ vs. $T$. The compound is in paramagnetic state until low temperature. The $\chi_{\mathrm{m}} T$ values of compound 1 changed smoothly upon cooling until they reach minima and then increase sharply to a value, which is a typical feature of ferrimagnetic behavior. $1 / \chi_{\mathrm{m}}$ obeys Curie-Weiss equation $\chi_{\mathrm{m}}=C_{\mathrm{m}} /(T-\theta)$ in the high temperature zone with the Curie constant of $21.06 \mathrm{emu} \cdot \mathrm{K} \cdot \mathrm{mol}^{-1}$ and the Weiss constant $\theta$ of $-0.023 \mathrm{~K}$, respectively. This indicates the existence of antiferromagnetic interaction in compound 1. The Acquired magnetic moment $\mu_{\text {eff }}=12.98 \mu_{\mathrm{B}}$ at $300 \mathrm{~K}$ derived from $\mu_{\text {eff }}=\left(8 \chi_{\mathrm{m}} T\right)^{1 / 2}$ is in good agreement with the calculated spin-only value for a magnetically uncoupled system of $\mu_{\text {eff }}=12 \mu_{\mathrm{B}}$ of which $\left[\mu_{\text {eff }}=g \Sigma S_{1}\left(S_{1}+1\right) \mu_{\mathrm{B}}\right.$ with $S_{1}=2$ for $\left.\mathrm{Fe}^{2+}\right]$.

\subsubsection{Magnetic properties of compound 2}

The temperature dependence of the magnetic measurement was performed on compound $\mathbf{2}$ in a temperature range from 2 to $300 \mathrm{~K}$ with an applied field of $5 \mathrm{kOe}$. Fig. S8 shows the temperature dependence of magnetic susceptibility measurements for the compound 2 in the form of $\chi_{\mathrm{m}} T$ and $1 / \chi_{\mathrm{m}}$ vs. T. $1 / \chi_{\mathrm{m}}$ obeys Curie-Weiss equation $\chi_{\mathrm{m}}=C_{\mathrm{m}} /(T-\theta)$ in the high temperature zone with the Curie constant of $12.4 \mathrm{emu} \cdot \mathrm{K} \cdot \mathrm{mol}^{-1}$ and the Weiss constant $\theta$ of $-17.9 \mathrm{~K}$, respectively. The $\chi_{\mathrm{m}} T$ product maintains a constant value of $11.7 \mathrm{emu} \cdot \mathrm{K} \cdot \mathrm{mol}^{-1}$ between 300 and $187 \mathrm{~K}$. Below this temperature the values of $\chi_{\mathrm{m}} T$ decreases to $0.48 \mathrm{emu} \cdot \mathrm{K} \cdot \mathrm{mol}^{-1}$. This indicates the existence of antiferromagnetic interaction in compound 2. Neel temperature for compound $\mathbf{2}$ is $18.03 \mathrm{~K}$. Above Neel temperature, compound 2 shows paramagnetic behavior. The Acquired magnetic moment $\mu_{\text {eff }}=9.67 \mu_{\mathrm{B}}$ at $300 \mathrm{~K}$ derived from $\mu_{\text {eff }}=\left(8 \chi_{\mathrm{m}} T\right)^{1 / 2}$ is in good agreement with the calculated spin-only value for a magnetically uncoupled system of $\mu_{\text {eff }}=9.11 \mu_{\mathrm{B}}$ of which $\left[\mu_{\text {eff }}=g \Sigma\left(S_{1}\left(S_{1}+1\right)+2 S_{2}\left(S_{2}+1\right)\right)^{1 / 2} \mu_{\mathrm{B}}\right.$ with $S_{1}=2$ for $\mathrm{Fe}^{2+}$ and $S_{2}=5 / 2$ for $\left.\mathrm{Fe}^{3+}\right]$.

\subsubsection{Magnetic properties of compound 3}

The temperature dependence of the magnetic measurement was performed on compound $\mathbf{3}$ in a temperature range from 2 to $300 \mathrm{~K}$ with an applied field of $5 \mathrm{kOe}$. As Fig. S9 shows the temperature dependence of magnetic susceptibility measurements for the compound 3 in the form of $\chi_{\mathrm{m}} T$ and $1 / \chi_{\mathrm{m}}$ vs. $T$. The compound is in paramagnetic state until low temperature. $1 / \chi_{\mathrm{m}}$ obeys Curie-Weiss equation $\chi_{\mathrm{m}}=C_{\mathrm{m}} /(T-\theta)$ in the high temperature zone with the Curie constant of $9.21 \mathrm{emu} \cdot \mathrm{K} \cdot \mathrm{mol}^{-1}$ and the Weiss constant $\theta$ of $-41.53 \mathrm{~K}$, respectively. This indicates the existence of antiferromagnetic interaction in compound 3. The Acquired magnetic moment $\mu_{\text {eff }}=8.04 \mu_{\mathrm{B}}$ at $300 \mathrm{~K}$ derived from $\mu_{\text {eff }}=\left(8 \chi_{\mathrm{m}} T\right)^{1 / 2}$ is in good agreement with the calculated spin-only value for a magnetically uncoupled system of $\mu_{\text {eff }}=8.37 \mu_{\mathrm{B}}$ of which $\left[\mu_{\text {eff }}=g \Sigma\left(2 S_{2}\left(S_{2}+1\right)\right)^{1 / 2} \mu_{\mathrm{B}}\right.$ with $S_{2}=5 / 2$ for $\left.\mathrm{Fe}^{3+}\right]$. 


\section{Conclusion}

In this work, three iron phosphites open-framework compounds have been synthesized in ionic liquid, and we also investigated how the gel concentrations, synthetic times and reaction temperatures affect the synthesis process by high-throught approaches. From a series of reactions, we have obtained the crystallization area of three compounds and selected the best reaction conditions which can generate the pure phase. Specially, ionic liquid ([Emim]Br) is decomposed into $\mathrm{NH}_{4}{ }^{+}$cation as a template agent to support the framework, which is used in compounds $\mathbf{1}$ and $\mathbf{2}$. Moreover, since the ionic liquid plays dual roles of template agent and solvent, we investigated the effect of different ionic liquids with different alkyl chains. Results show that the change of ionic liquid cannot produce compounds $\mathrm{Fe}_{5}^{\Pi}\left(\mathrm{NH}_{4}\right)_{2}\left(\mathrm{HPO}_{3}\right)_{6}(\mathbf{1})$ and $\mathrm{Fe}_{2}{ }_{2} \mathrm{Fe}^{\mathrm{m}}\left(\mathrm{NH}_{4}\right)\left(\mathrm{HPO}_{3}\right)_{4}(\mathbf{2})$, only the dense phase $\mathrm{Fe}_{2}{ }_{2}\left(\mathrm{HPO}_{3}\right)_{3}(\mathbf{3})$ and the amorphous phase were obtained. The thermal stability and magnetic properties were also studied. We expect lots of open-framework materials with unique physical and chemical properties will be synthesized by ionothermal conditions and applied in industrial production as soon as possible.

\section{Footnotes}

In this paper, the crystallographic data of compound $\mathbf{1}$ comes from the Cambridge Crystallographic Data Centre (CCDC reference: 1027279)

\section{Acknowledgments}

We thank the National Science Foundation for Young Scientists of China (Grant: 21501062), the National Key Research and Development Program of China (No. 2016YFB0701100), the Research Project of the Science and Technology of Jilin Province, China (Grant: 201413001) and the Open Project of the State Key Laboratory of Inorganic Synthesis and Preparative Chemistry (Grant: 2015-31) for financial support of this work.

We are grateful to MiLan Liu for her aid in the measurement of the Mössbauer spectroscopy, Jilin University. We heartfelt thanks to the referees, Yi Li(State Key Laboratory of Inorganic Synthesis and Preparative Chemistry, College of Chemistry, Jilin University) and Hongzhu Xing(College of Chemistry, Northeast Normal University) for their helpful and kind suggestions.

\section{References}

[1] X.D. Xiang, I. Takeuchi., Combinatorial Materials Science, Eds., Dekker: New York, 2003.

[2] J.X. Jiang, Y. Xu, P. Cheng, Q.M. Sun, J.H. Yu, A. Corma, R.R. Xu, Chem. Mater. 23 ( 2011) 4709-4715.

[3] Y. Li, X. Li, J.C. Liu, F.Z. Duan, J.H. Yu, Nat. Commun. 6 (2015) 8328.

[4] D.E. Akporiaye, I.M. Dahl, A. Karlsson, R. Wendelbo, Angew. Chem. Int. Ed. 37 (1998) 609-611.

[5] A. Corma, M. Moliner, J.M. Serra, P. Serna, M.J. Díaz-Cabañas, L.A. Baumes, Chem. Mater. 18 (2006) 3287-3296

[6] J. Klein, C.W. Lehmann, H.W. Schmidt, W.F. Maier, Angew. Chem. Int. Ed. 37 (1998) 3369-3372.

[7] K. Choi, D. Gardner, N. Hilbrandt, T. Bein, Angew. Chem. Int. Ed. 38 (1999) 2891-2894.

[8] Y. Song, J.H. Yu, G.H. Li, Y. Li, Y. Wang, R.R. Xu, Chem. Commun. (2002) 1720-1721.

[9] A. Corma, M. J. Díaz-Cabañas, J. L. Jorda, C. Martinez, M. Moliner, Nature 443 (2006) 842-845.

[10] J.X. Jiang, J. L. Jorda, M.J. Díaz-Cabañas, J.H. Yu, A. Corma, Angew. Chem. Int. Ed. 49 (2010) 4986-4988.

[11] Y.D. Han, Y. Li, J.H. Yu, Q.H. Pan, R.R. Xu, Eur. J. Inorg. Chem. 2012 (2012) 36-39.

[12] Y.N. Guo, X.W. Song, J.Y. Li, Y. Li, Y.D. Han, J.H. Yu, R.R. Xu, Dalton Trans. 40 (2011) 9289-9294.

[13] Y.Y. Wang, L. Shao, Y. Li, X. Li, J.Y. Li, J.H. Yu, R.R. Xu, Dalton Trans. 41(2012) 6855-6860.

[14] L. Shao, Y. Li, J.H. Yu, R.R. Xu, Inorg. Chem. 51 (2012) 225-229.

[15] Y.Y. Wang, Y. Li, L. Wang, J.Z. Zhang, Y. Yan, J.Y. Li, J.H. Yu, J.C. Wang, R.R. Xu, Inorg. Chem. 50(2011) 
1820-1825.

[16] L. Li, T. Su, J.Y. Li, J. Xu, J.H. Yu, R.R. Xu, Inorg. Chim. Acta. 370 (2011) 65-69.

[17] C.N.R. Rao, S. Natarajan, A. Choudhury, S. Neeraj, A.A. Ayi, Acc. Chem. Res. 34 (2001) 80-87.

[18] R. Murugavel, A. Choudhury, M.G. Walawalkar, R. Pothiraja, C.N.R. Rao, Chem. Rev. 108 (2008) 3549-3655.

[19] S. Natarajan, S. Mandal, Angew. Chem. Int. Ed. 47 (2008) 4798-4828.

[20] Z.J. Dong, Y. Yan, W.Q. Zhang, Y. Wang, J.Y. Li, Chem. Res. Chin. Univ. 31 (2015) 498-502.

[21] J. Liang, J.Y. Li, J.H. Yu, P. Chen, Q.R. Fang, F.X. Sun, R.R. Xu, Angew. Chem. Int. Ed. 45 (2006) 2546-2548.

[22] J. Liang, J.Y. Li, J.H. Yu, P. Chen, L. Li, R.R. Xu, J. Solid State Chem. 179 (2006) 1977-1983.

[23] J. Orive, E.S. Larrea, R.F. de Luis, M. Iglesias, J.L. Mesa, T. Rojo, M.I. Arriortua, Dalton Trans. 42 (2013) 4500-4512.

[24] X.M. Jing, L.R. Zhang, S.Z. Gong, G.H. Li, M.H. Bi, Q.S. Huo, Y.L. Liu, Microporous Mesoporous Mater. 116 (2008) 101-107.

[25] H. Zhang, L.P. Wang, T.Y. Song, L. Wang, S.H. Shi, L. Yang, Chem. Res. Chin. Univ. 25 (2009) 417-420.

[26] L. Liu, L.R. Zhang, X.F. Wang, G.H. Li, Y.L. Liu, W.Q. Pang, Dalton Trans. (2008) 2009-2014.

[27] X.M. Jing, Y.B. Tan, L.W. Xiao, Y.L. Liu, Inorg. Chem. Commun. 57 (2015) 75-77.

[28] L. Liu, D.B. Luo, D.F. Li, Z. Lin, Dalton Trans. 43 (2014) 7695-7698.

[29] X.L. Wang, Y. Yan, J.B. Wu, Z.J. Dong, L. Li, J.Y. Li, Z. Anorg. Allg. Chem. 639 (2013) 2343-2346.

[30] X.C. Liu, Y. Xing, X.L. Wang, H.B. Xu, X.Z. Liu, K.Z. Shao, Z.M. Su, Chem. Commun. 46 (2010) 2614-2616.

[31] G. Li, Y. Xing, S. Song, J. Solid State Chem.181 (2008) 943-949.

[32] L. Zhao, J.Y. Li , P. Chen, G.H. Li, J.H. Yu, R.R. Xu, Chem. Mater. 20 (2008) 17-19.

[33] S. Fernandez, J.L. Pizarro, J.L. Mesa, L. Lezama, M.I. Arriortua, T. Rojo, Int. J. Inorg. Mater. 3 (2001) 331-336.

[34] Z.E. Lin, H.P. Nayek, S. Dehnen, Microporous Mesoporous Mater. 126 (2009) 95-100.

[35] S. Fernandez, J.L. Mesa, J.L. Pizarro, L. Lezama, M.I. Arriortua, R. Olazcuaga, T. Rojo, Chem. Mater. 12 (2000) 2092-2098.

[36] U.C. Chung, J.L. Mesa, J. L Pizarro, L. Lezama, J.S. Garitaonandia, J.P. Chapman, M.I. Arriortua, J. Solid State Chem. 177 (2004) 2705-2713.

[37] S. Fernández-Armas, J.L. Mesa, J.L Pizarro, J.S. Garitaonandia, M.I. Arriortua, T. Rojo, Angew. Chem. Int. Ed. 43 (2004) 977-980.

[38] Y. Fan, T.Y. Song, G.H. Li, Z. Shi, G.H. Yu, J.N. Xu, S.H. Feng, Inorg. Chem. Commun. 8 (2005) 661-664.

[39] S. Fernández-Armas, J.L. Mesa, J.L. Pizarro, U.C. Chung, M.I. Arriortua, T. Rojo, J. Solid State Chem. 178 (2005) 3554-3562.

[40] S. Mandal, S.K. Pati, M.A. Green, S. Natarajan, Chem. Mater. 17 (2005) 638-643.

[41] W. Liu, H.H. Chen, X.X. Yang, J.T. Zhao, Eur. J. Inorg. Chem. 2005 (2005) 946-951.

[42] J.L. Cisneros, S. Fernández-Armas, J.L. Mesa, J. L. Pizarro, M.I. Arriortúa, T. Rojo, Mater. Res. Bull. 41 (2006) 2168-2180.

[43] S. Fernández-Armas, J.L. Mesa, J.L. Pizarro, M.I. Arriortua, T. Rojo, Mater. Res. Bull. 42 (2007) 544-552.

[44] P.M. Sghyar, J. Durand, L. Cot, Acta Cryst. C. 47 (1991) 2515-2517.

[45] S. Mandal, S. Natarajan, Chem. Eur. J. 13 (2007) 968-977.

[46] S.Mandal, D. Banerjee, S.V. Bhat, S.K. Pati, S. Natarajan, Eur. J. Inorg. Chem. 2008 (2008) 1386-1391.

[47] S. Natarajan, S. Mandal, Angew. Chem. Int. Ed. Engl. 47 (2008) 4798-4828. 
[48] L. Liu, X. Wang, L. Xu, X. Liu, L. Liu, B. Bi, W. Pang , Inorg. Chim. Acta. 362 (2009) 3881-3884.

[49] J. Orive, J.L. Mesa, E. Legarra, F. Plazaola, M.I. Arriortua, T. Rojo, J. Solid State Chem. 182 (2009) 2191-2201.

[50] J. Qiao, L.R. Zhang, Y. Yu, G.H. Li, T.C. Jiang, Q.S. Huo, Y.L. Liu, J. Solid State Chem. 182 (2009) 1929-1934.

[51] J.L. Cisneros, S. Fernández-Armas, J.L. Mesa, J.L. Pizarro, M.I. Arriortúa, T. Rojo, Mater. Res. Bull. 41 (2006) 1835-1844.

[52] T. Rojo, J.L. Mesa, J. Lago, B. Bazan, J.L. Pizarro, M.I. Arriortua, J. Mater. Chem. 19 (2009) 3793-3818.

[53] B.S. Zakharova, A.B. Ilyukhin, Crystallogr. Rep. 55 (2010) 15-18.

[54] U.C. Chung, J.L. Mesa, J.L. Pizarro, I. de Meatza, M. Bengoechea, J. Rodríguez Fernández, M.I. Arriortua, T. Rojo, Chem.Mater. 23 (2011) 4317-4330.

[55] F. Hamchaoui, V. Alonzo, D. Venegas-Yazigi, H. Rebbah, E. Le Fur, J. Solid State Chem. 198 (2013) 295-302.

[56] T. Berrocal, J. L. Mesa, E. Larrea, J.M. Arrieta, Acta Crystallogr. E 70 (2014) 309-311.

[57] F. Hamchaoui, V. Alonzo, H. Rebbah, E. Le Fur, Acta Crystallogr., Sect. C, Struct. Chem. 70 (2014) 351-354.

[58] E.R. Cooper, C.D. Andrews, P.S. Wheatley, P.B. Webb, P. Wormald, R.E. Morris, Nature 430 (2004) 1012-1016.

[59] Y.P. Xu, Z.J. Tian, S.J. Wang, Y. Hu, L. Wang, B.C. Wang, Y.C. Ma, L. Hou, J.Y. Yu, L.W. Lin, Angew. Chem. Int. Ed. 45 (2006) 3965-3970.

[60] Y. Wei, Z.J. Tian, H. Gies, R.S. Xu, H.J. Ma, R.Y. Pei, W.P. Zhang, Y.P. Xu, L. Wang, K.D. Li, B.C. Wang, G.D. Wen, L.W. Lin, Angew. Chem. Int. Ed. 49 (2010) 5367-5370.

[61] L. Wang, Y.P. Xu, B.C. Wang, S.J. Wang, J.Y. Yu, Z.J. Tian, L.W. Lin, Chem. Eur. J. 14 (2008) 10551-10555

[62] R.S. Xu, W.P. Zhang, J. Guan, Y.P. Xu, L. Wang, H.J. Ma, Z.J. Tian, X.W. Han, L.W. Lin, X.H. Bao, Chem. Eur. J. 15 (2009) 5348-5354.

[63] H.Z. Xing, J.Y. Li, W.F. Yan, P. Chen, Z. Jin, J.H. Yu, S. Dai, R.R. Xu, Chem. Mater. 20 (2008) 4179-4181.

[64] D. Nakamura, I. Gunjishima, S. Yamaguchi, T. Ito, A. Okamoto, H. Kondo, S. Onda, K. Takatori, Nature 430 (2004) 1009-1012.

[65] R.D. Rogers, K.R. Seddon, Science 302 (2003) 792-793.

[66] P. Bonhôte, A.P. Dias, N. Papageorgiou, K. Kalyanasundaram, M. Grätzel, Inorg. Chem. 35 (1996) 1168-1178.

[67] R.E. Morris, Angew.Chem. Int. Ed. Engl. 47 (2008) 442-444.

[68] R.E. Morris, Chem. Commun.(Camb). (2009) 2990-2998.

[69] E.R. Parnham, R.E. Morris, Chem. Mater. 18 (2006) 4882-4887.

[70] Z. Ma, J.H. Yu, S. Dai, Adv. Mater. 22 (2010) 261-285.

[71] R. Cai, Y. Liu, S. Gu, Y.S. Yan, J. Am. Chem. Soc. 132 (2010) 12776-12777.

[72] J.D. Feng, S.W. Tang, K.Z. Shao, R.S. Wang, C. Yao, H.M. Xie, Z.M. Su, Crystengcomm. 12 (2010) 3448-3451.

[73] J.D. Feng, K.Z. Shao, S.W. Tang, R.S. Wang, Z.M. Su, Crystengcomm. 12 (2010) 1401-1403.

[74] H.Z. Xing, W.T. Yang, T. Su, Y. Li, J. Xu, T. Nakano, J.H. Yu, R.R. Xu, Angew. Chem. Int. Ed. 49 (2010) 2328-2331.

[75] T. Su, H.Z. Xing, Y. Li, J.B. Wu, X.W. Song, T. Nakano, J.H. Yu, Inorg. Chem. Front. 3 (2016) 924-927.

[76] SMART and SAINT software packages, Siemens Analytical X-ray Instruments, Inc., Madison, WI, 1996.

[77] Sheldrick, G. M. SHELXL Program, version 5.1, Siemens Industrial Automation, Inc., Madison, WI, 1997. 
Table 1. Crystallization field diagram for all compounds.

\begin{tabular}{|c|c|c|c|c|}
\hline $\begin{array}{c}\text { Crystallisation } \\
\left.\text { time/Temp. }{ }^{\circ} \mathrm{C}\right]\end{array}$ & $5 \mathrm{~d}$ & $10 \mathrm{~d}$ & $15 \mathrm{~d}$ & $20 \mathrm{~d}$ \\
\hline 140 & $\mathbf{3}$ & $\mathbf{3}$ & $\mathbf{3}$ & $\mathbf{3}$ \\
\hline 150 & $\mathbf{3}$ & $\mathbf{2 + 3}$ & $\mathbf{2 + 3}$ & $\mathbf{2}+\mathbf{3}$ \\
\hline 160 & $\mathbf{1 + 3}$ & $\mathbf{1 + 3}$ & $\mathbf{1 + 3}$ & $\mathbf{1 + 3}$ \\
\hline 180 & $\mathbf{1}+\mathbf{3}$ & $\mathbf{1}$ & $\mathbf{1}$ & $\mathbf{1}$ \\
\hline 200 & Amorphism & Amorphism & Amorphism+1 & Amorphism \\
\hline
\end{tabular}


Table 2. Crystallization field diagram for all four different ionic liquids at the optimal reaction conditions.

\begin{tabular}{|c|c|c|c|c|}
\hline Ionic Liquid/ Temp. $\left[{ }^{\circ} \mathrm{C}\right]$ & {$[\mathrm{Emim}] \mathrm{Br}$} & {$[\mathrm{Prmim}] \mathrm{Br}$} & {$[\mathrm{Bmim}] \mathrm{Br}$} & {$[\mathrm{Pemim}] \mathrm{Br}$} \\
\hline 140 & $\mathbf{3}$ & $\mathbf{3}$ & $\mathbf{3}$ & $\mathbf{3}$ \\
\hline 150 & $\mathbf{2 + 3}$ & Amorphism & $\mathbf{3}$ & $\mathbf{3}$ \\
\hline 160 & $\mathbf{1}+\mathbf{1 + 3}$ & Amorphism & Amorphism & $\mathbf{3}$ \\
\hline 180 & Amorphism & Amorphism & $\mathbf{3}$ \\
\hline 200 & Amorphism+1 & Amorphism & Amorphism & Amorphism \\
\hline
\end{tabular}


Table 3. Crystal data and structure refinement for compounds $\mathbf{1}, \mathbf{2}$ and $\mathbf{3}$.

\begin{tabular}{|c|c|c|c|}
\hline Compound & 1 & 2 & 3 \\
\hline Empirical formula & $\mathrm{Fe}_{5} \mathrm{H}_{14} \mathrm{~N}_{2} \mathrm{O}_{18} \mathrm{P}_{6}$ & $\mathrm{Fe}_{3} \mathrm{H}_{8} \mathrm{NO}_{12} \mathrm{P}_{4}$ & $\mathrm{H}_{0.50} \mathrm{Fe}_{0.33} \mathrm{O}_{1.50} \mathrm{P}_{0.50}$ \\
\hline Formula weight & 795.20 & 505.50 & 58.61 \\
\hline Temperature & $100.0(1) \mathrm{K}$ & 293(2) K & 293(2) K \\
\hline Wavelength & $0.71073 \AA$ & $0.71073 \AA$ & $0.71073 \AA$ \\
\hline Crystal system & Trigonal & Monoclinic & Hexagonal \\
\hline space group & $P \overline{3} c 1$ & $P 2_{1} / c$ & $P 6_{3} / m$ \\
\hline \multirow[t]{6}{*}{ Unit cell dimensions } & $a=10.38(6) \AA$ & $a=12.43(7) \AA$ & $a=8.051(6) \AA$ \\
\hline & $\alpha=90^{\circ}$ & $\alpha=90^{\circ}$ & $\alpha=90^{\circ}$ \\
\hline & $b=10.38(6) \AA$ & $b=10.16(1) \AA$ & $b=8.051(6) \AA$ \\
\hline & $\beta=90^{\circ}$ & $\beta=100.05^{\circ}$ & $\beta=90^{\circ}$ \\
\hline & $c=9.208(9) \AA$ & $c=9.309(3) \AA$ & $c=7.328(5) \AA$ \\
\hline & $\gamma=120^{\circ}$ & $\gamma=90^{\circ}$ & $\gamma=120^{\circ}$ \\
\hline Volume & $860.3(3) \AA^{3}$ & $1158.5 \AA^{3}$ & $411.44 \AA^{3}$ \\
\hline$Z$, Calculated density & $2,3.073 \mathrm{Mg} / \mathrm{m}^{3}$ & $4,2.898 \mathrm{Mg} / \mathrm{m}^{3}$ & $12,2.838 \mathrm{Mg} / \mathrm{m}^{3}$ \\
\hline Absorption coefficient & $4.780 \mathrm{~mm}^{-1}$ & $4.324 \mathrm{~mm}^{-1}$ & $4.134 \mathrm{~mm}^{-1}$ \\
\hline$F(000)$ & 784 & 996 & 344 \\
\hline Crystal size & $0.03 \times 0.001 \times 0.001 \mathrm{~mm}$ & $0.20 \times 0.06 \times 0.04 \mathrm{~mm}$ & $0.63 \times 0.24 \times 0.23 \mathrm{~mm}$ \\
\hline $\begin{array}{l}\text { Theta range for data } \\
\text { collection. }\end{array}$ & $2.3^{\circ}$ to $28.3^{\circ}$ & $3.23^{\circ}$ to $28.57^{\circ}$ & $5.57^{\circ}$ to $34.34^{\circ}$ \\
\hline \multirow[t]{2}{*}{ Limiting indices } & $-13 \leq h \leq 11,-10 \leq k \leq 13$ & $-15 \leq h \leq 10,-11 \leq k \leq 12$ & $-12 \leq h \leq 9,-7 \leq k \leq 10$ \\
\hline & $11 \leq l \leq 1$ & $12 \leq l \leq 12$ & $11 \leq l \leq 11$ \\
\hline Reflections collected / & $6343 /$ & $4620 /$ & $2391 /$ \\
\hline unique & $659[R($ int $)=0.073]$ & $2610[R(\mathrm{int})=0.0344]$ & $550[R(\mathrm{int})=0.0314]$ \\
\hline Data / restraints / parameters & $659 / 15 / 68$ & $2610 / 8 / 205$ & $550 / 0 / 28$ \\
\hline Goodness-of-fit on $F^{2}$ & 1.156 & 1.052 & 1.207 \\
\hline \multirow[t]{2}{*}{ Final $R$ indices $[I>2 \sigma(I)]$} & $R_{1}=0.033$ & $R_{1}=0.0337$ & $R_{1}=0.0336$ \\
\hline & $w R_{2}=0.0632$ & $w R_{2}=0.0835$ & $w R_{2}=0.0853$ \\
\hline \multirow[t]{2}{*}{$R$ indices (all data) } & $R_{1}=0.036$ & $R_{1}=0.0427$ & $R_{1}=0.0420$ \\
\hline & $w R_{2}=0.0651$ & $w R_{2}=0.0892$ & $w R_{2}=0.0884$ \\
\hline Largest diff. peak and hole & 0.530 and -0.760 e. $\AA^{-3}$ & 1.148 and -0.600 e. $\AA^{-3}$ & 0.822 and -0.778 e. $\AA^{-3}$ \\
\hline
\end{tabular}


Table 4. Isomer shift (IS) relative to $\alpha$-Fe metal, quadrupole splitting (QS), the value of width at half-maximum (WHM) and area ratio of ${ }^{57} \mathrm{Co} / \mathrm{Pd}$ Mössbauer spectrum.

\begin{tabular}{lllll}
\hline Cation & $\mathrm{IS}(\mathrm{mm} / \mathrm{s})$ & $\mathrm{QS}(\mathrm{mm} / \mathrm{s})$ & WHM $(\mathrm{mm} / \mathrm{s})$ & Area Ratio $(\%)$ \\
\hline $\mathrm{Fe}^{\mathrm{II}}$ & $0.30 \pm 0$ & $0.57 \pm 0$ & $0.17 \pm 0$ & 29.4 \\
$\mathrm{Fe}^{\mathrm{I}}$ & $1.28 \pm 0$ & $1.74 \pm 0$ & $0.20 \pm 0$ & 37.3 \\
$\mathrm{Fe}^{\mathrm{II}}$ & $1.37 \pm 0$ & $2.15 \pm 0$ & $0.18 \pm 0$ & 33.3 \\
\hline
\end{tabular}



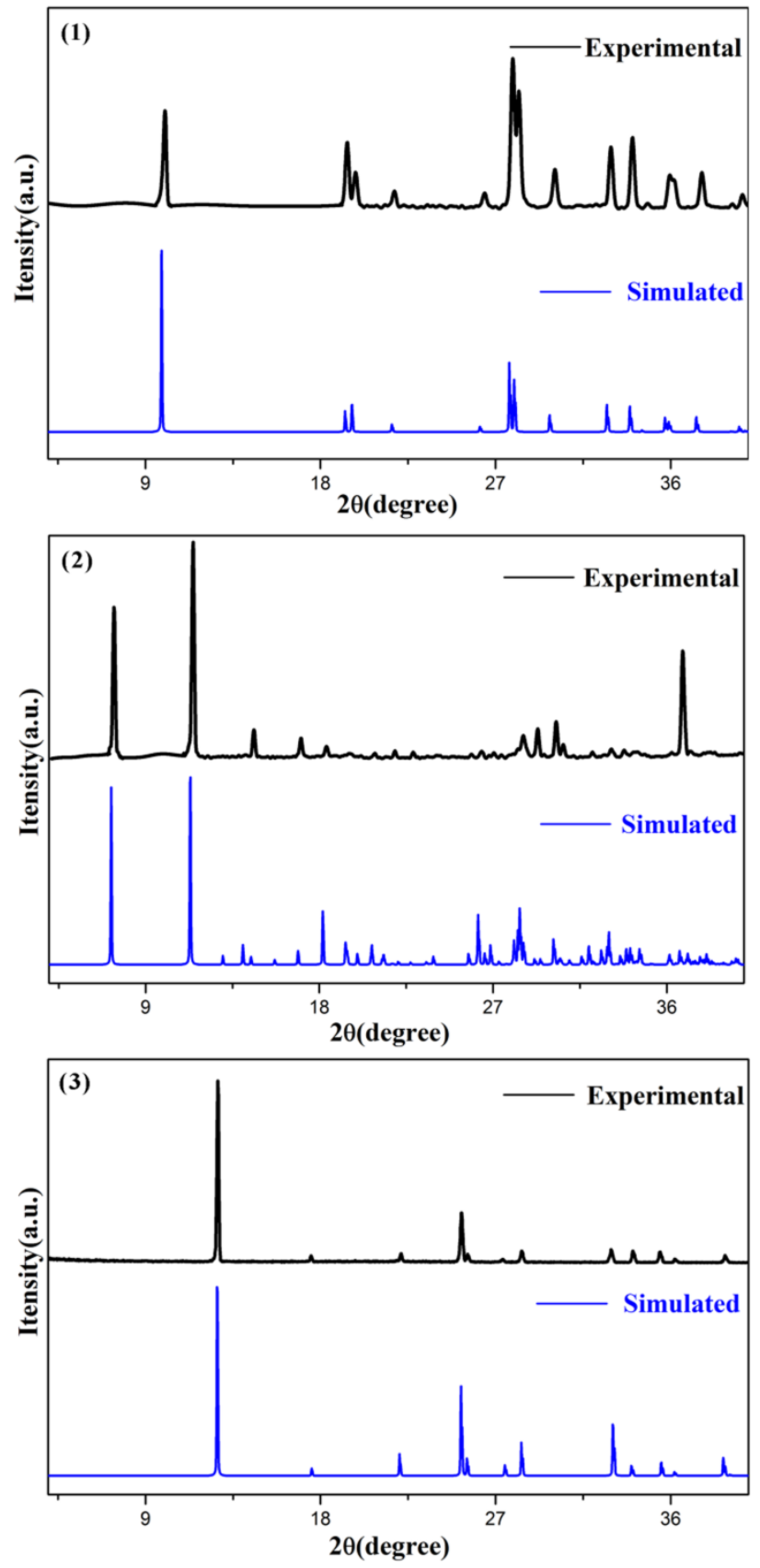

Fig. 1. Simulated and experimental X-ray powder diffraction patterns of compounds 1, 2 and $\mathbf{3}$. 

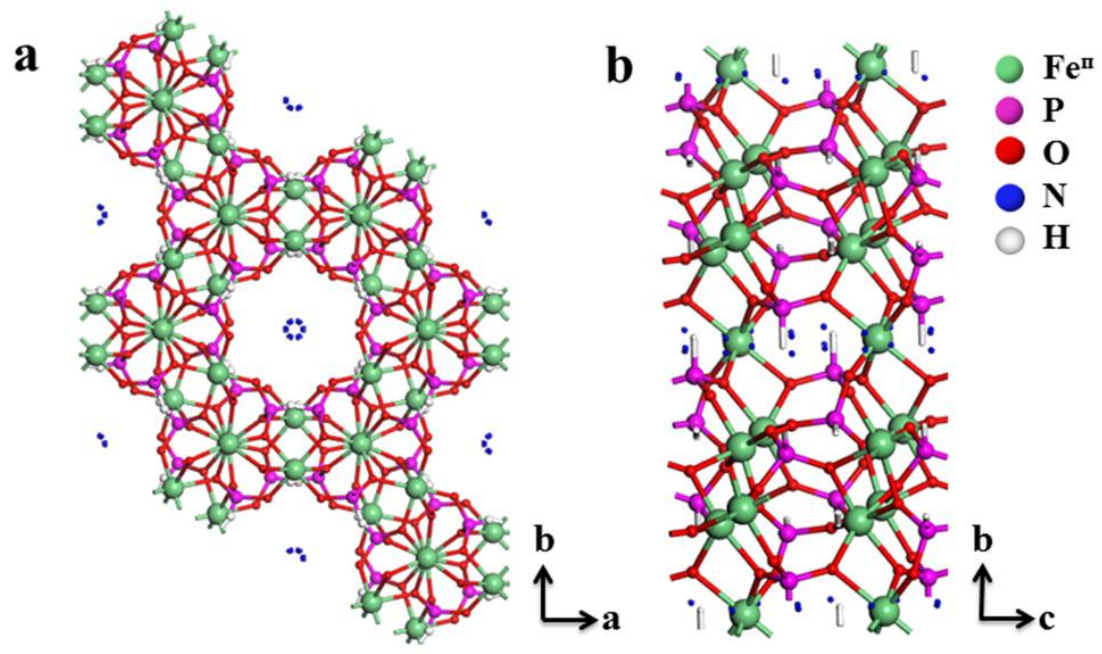

Fig. 2. (a) Ball-stick view of compound 1 projected along the [001] directions. (b) Ball-stick view of compound $\mathbf{1}$ projected along the [100] directions. 


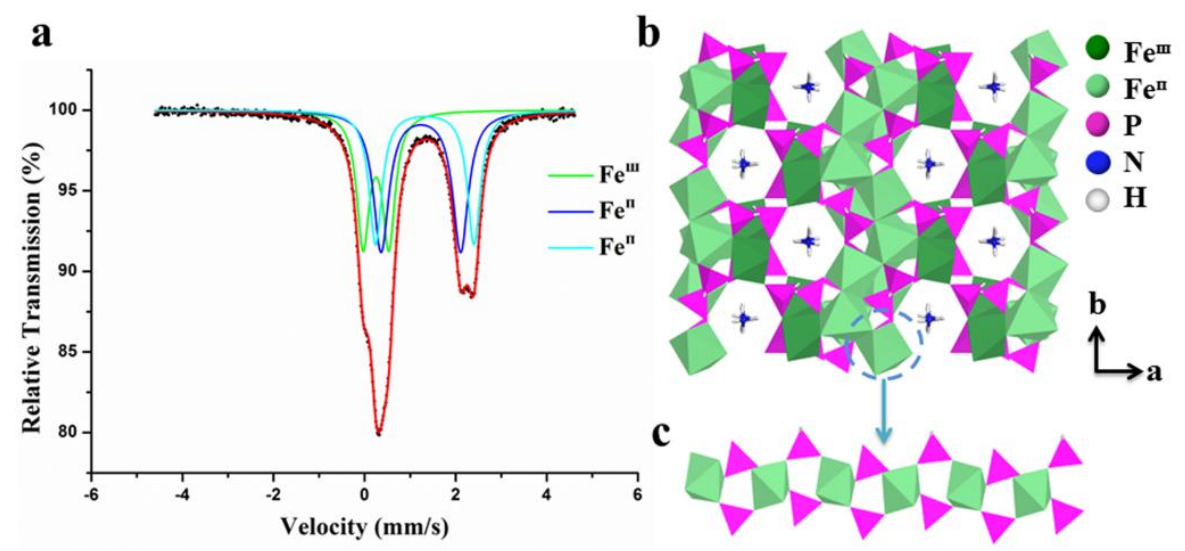

Fig. 3. (a) Mössbauer spectrum of compound $\mathbf{2}$ at ambient temperature. (b) Polyhedral view of compound 2 projected along the [001] directions. (c) Corner-sharing chain. Oxygen atoms of the inorganic sheet are omitted for clarity. 


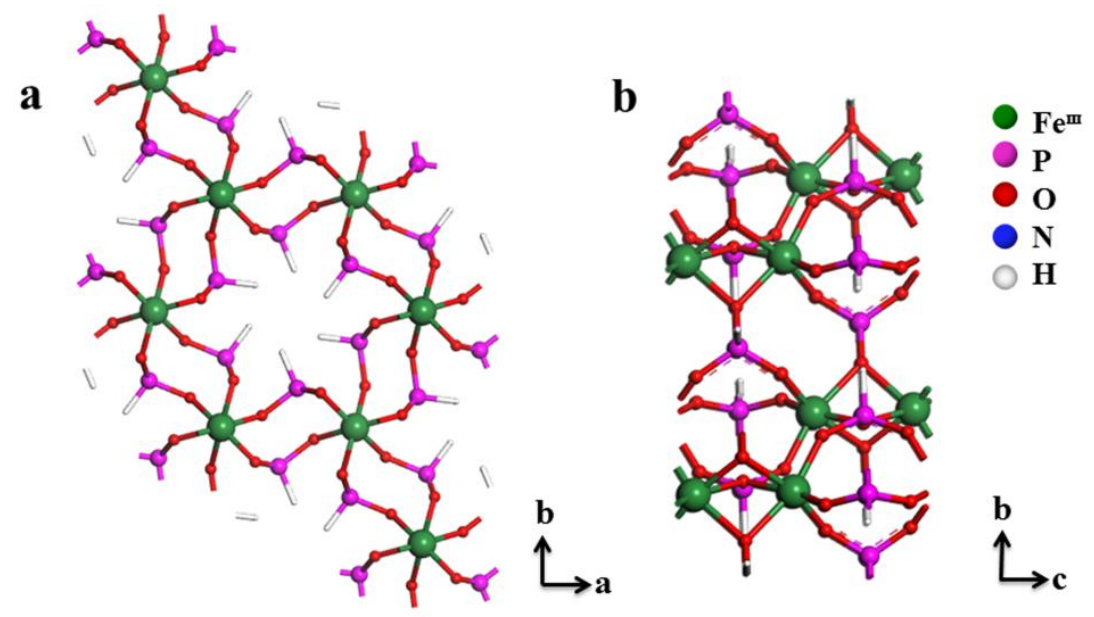

Fig. 4. (a) Ball-stick view of compound $\mathbf{3}$ projected along the [001] directions. (b) Ball-stick view of compound $\mathbf{3}$ projected along the [100] directions. 


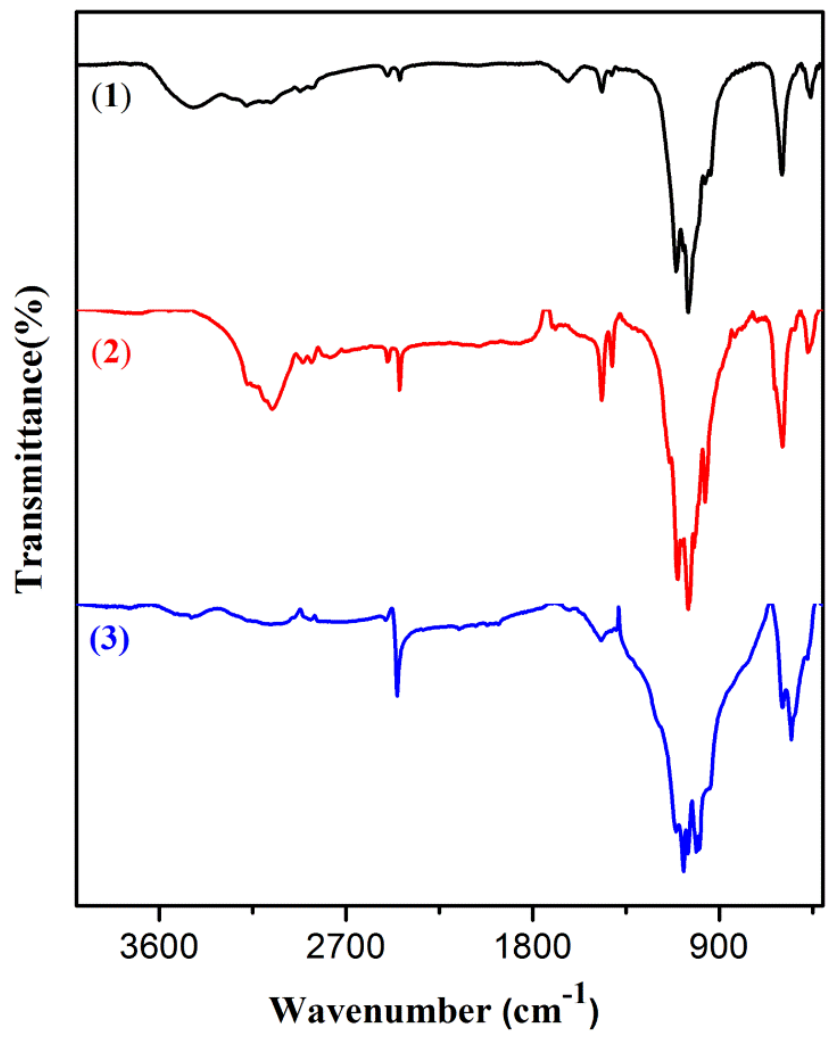

Fig. 5. IR spectra of compounds $\mathbf{1}, \mathbf{2}$ and $\mathbf{3}$. 
TOC: Three iron phosphites open-framework compounds have been synthesized in ionic liquid and we have investigated how the gel concentrations, synthetic times and reaction temperatures affect the synthesis process by using high-throughput approach.

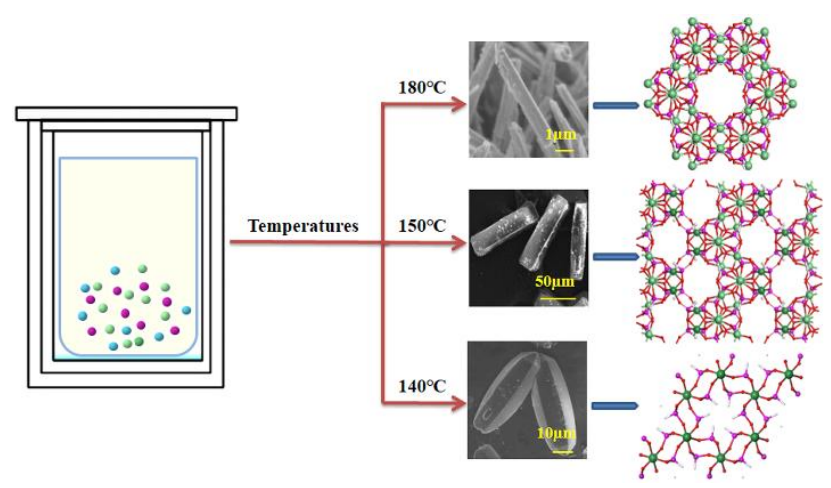

